\title{
NUMERICAL MODEL OF 3D MORPHODYNAMIC AFTER OFFSHORE NOURISHMENT
}

\author{
Masamitsu Kuroiwa ${ }^{1}$, Yoko Shibutani ${ }^{1}$, Yuhei Matsubara ${ }^{1}$ \\ Takayuki Kuchiishi $^{2}$ and Mazen Abualtyef ${ }^{1}$
}

\begin{abstract}
A three-dimensional model of morphodynamics after offshore nourishment was developed. In the presented model, the $3 \mathrm{D}$ beach evolution model that is not only after nourishment but also taking into account the nourishment process of injected sand material. In order to consider the injected process of sand, the computation using the advectiondiffusion equation for suspended sediment concentration was adapted in the model. The presented model was applied to an idealized beach with two groins in order to investigate the performance of the model, and then, the model was applied to a field observation result for shoreface nourishment carried out at the Egmond aan Zee in the Netherlands. Finally, the applicability of the presented model was discussed from the computed results.
\end{abstract}

Keywords: offshore nourishment; sediment transport; morphodynamics; nearshore currents; numerical simulation

\section{INTRODUCTION}

The techniques for protecting sandy beach have been changed from "hard engineering" using the coastal structures into "soft engineering" such as sand nourishments. The sand nourishment is not only an effective technique for recovering eroded beaches but also for maintaining the ecological environments. In general, the nourished materials are injected near shoreline. The nourishments near shoreline effectively act to recovery of the eroded beaches. However, in case that there are some problems such as transportations and costs, sediments are injected in offshore area within critical water depth. Recently, the offshore nourishment such as shoreface nourishment (e.g. van Duin et al., 2004; Grunnet and Ruessink, 2005; Ojeda et al., 2008) has been employed to improve the coastal stability. Although the shoreface nourishment did not directly contribute the shoreline advances, however, the nourishment effectively acted as a submerged breakwater to reduce the high wave and to control the nearshore currents behind the nourished area (van Duin et al., 2004).

To evaluate the effect of the sand nourishment such the shoreface nourishment, a predictive model is required. Although some models based on N-Line model (e.g. Hanson et al., 2000; Uda et al.,2004; Shibutani et al., 2008) have been proposed, it seems to be difficult for applying the complicated bathymetry changes such as the rip-channel and offshore bar. Therefore, the 3D model so called coastal area model (e.g. de Vriend et al., 1993; Lesser et al., 2004) may be effective to the complicated bathymetry changes.

The purpose of this study is to develop a numerical model that can predict 3D morphodynamics after offshore sand nourishment such as the shoreface nourishment. In this study, the previous model presented by Kuroiwa et al. $(2004,2008)$ is modified to be capable to simulate the nourishing process of sand and the 3D morphodynamcs after the nourishment. A model test associated with offshore nourishment is carried out. Furthermore, the applicability of the presented model to field site is investigated.

\section{NUMERICAL MODEL}

The proposed 3D model is based on the hybrid model, which was proposed by Kuroiwa et al. (2006). The model consists of three modules, which are computations of (1) wave, (2) nearshore current, and (3) sediment transport rate and water depth change, as shown in Fig. 1.

\section{Wave Field}

The wave field is determined by the energy balance equation with energy dissipation and diffraction terms (EBED) presented by Mase (2001). The governing equation, for steady stare, is expressed by

$$
\frac{\partial\left(S v_{x}\right)}{\partial x}+\frac{\partial\left(S v_{y}\right)}{\partial y}+\frac{\partial\left(S v_{\theta}\right)}{\partial \theta}=\frac{\kappa}{2 \omega}\left\{\left(C C_{g} S_{y} \cos ^{2} \theta\right)_{y}-\frac{1}{2} C C_{g} S_{y y} \cos ^{2} \theta\right\}-D_{b}
$$

\footnotetext{
${ }_{2}^{1}$ Department of Civil Engineering, Tottori University, 4-101,Koyama, Tottori,680-8552, Japan

2 IDEA Consultants, Inc, 3-15-1,Komazawa Setagaya-ku,Tokyo,154-8585, Japan
} 
where $S$ is the angular-frequency spectral density. $v_{x}, v_{y}$ and $v_{\theta}$ are the propagation velocities. $\theta$ is the wave direction. $C$ is the wave celerity and $C_{g}$ is the group velocity. The first term on the right side represents the diffraction term. $\kappa$ is the free parameter to be optimized in order to change the degree of diffraction effect. The parameter is set at 2.5. The second term on the right side represents the energy dissipation rate due to wave breaking. In the computation of Eq.(1), the JONSWAP spectrum and the Mitsuyasu angular spreading function are employed. Significant wave height and mean wave direction at each grid point are calculated, and the root-mean square wave height $H_{r m s}$ is determined by using the relationship of $H_{1 / 3}=1.416 H_{r m s}$.

\section{Nearshore Current}

The nearshore current field is determined by the depth-averaged (2DH) mode or quasi-3D (Q-3D) mode in the hybrid model, according to the wave condition and prediction period. The $2 \mathrm{DH}$ mode is based on the model of Nisimura (1988). The Q-3D is selected when the undertow field in the surf zone should be estimated under stormy waves and then the Q-3D mode is based on the model using the fractional step method (Kuroiwa et al, 1998). The equations of motion and continuity are represented by

$$
\left.\begin{array}{c}
\frac{d U}{d t}=-g \frac{\partial \bar{\zeta}}{\partial x}-\frac{\partial R_{x x}}{\partial x}-\frac{\partial R_{x y}}{\partial y}+\frac{\partial}{\partial x}\left(v_{h} \frac{\partial U}{\partial x}\right)+\frac{\partial}{\partial y}\left(v_{h} \frac{\partial U}{\partial y}\right)+\frac{\partial}{\partial z}\left(v_{v} \frac{\partial U}{\partial z}\right) \\
\left.\begin{array}{c}
\frac{d V}{d t}=-g \frac{\partial \bar{\zeta}}{\partial y}-\frac{\partial R_{y x}}{\partial x}-\frac{\partial R_{y y}}{\partial y}+\frac{\partial}{\partial x}\left(v_{h} \frac{\partial V}{\partial x}\right)+\frac{\partial}{\partial y}\left(v_{h} \frac{\partial V}{\partial y}\right)+\frac{\partial}{\partial z}\left(v_{v} \frac{\partial V}{\partial z}\right)
\end{array}\right\} \\
\frac{\partial U}{d x}+\frac{\partial V}{\partial y}+\frac{\partial W}{\partial z}=0 \\
\frac{\partial \bar{\zeta}}{\partial t}+\frac{\partial \tilde{U}(h+\bar{\zeta})}{\partial x}+\frac{\partial \tilde{V}(h+\bar{\zeta})}{\partial y}=0
\end{array}\right\}
$$

where $U, V$ and $W$ are the local nearshore current velocities in the cross-shore $(x)$, alongshore $(y)$ and vertical $(z)$ directions, respectively. $\tilde{U}$ and $\tilde{V}$ are the depth-averaged current velocities. $\bar{\zeta}$ is the mean water level. $R_{x x}, R_{x y}, R_{y x}$ and $R_{y y}$, represent the excess momentum fluxes based on the linear wave theory. $v_{v}$ and $v_{h}$ represent the turbulent eddy viscosity coefficients in the vertical and horizontal directions, respectively. Some parameters used in this current module are introduced by Kuchiishi et al. (2004).

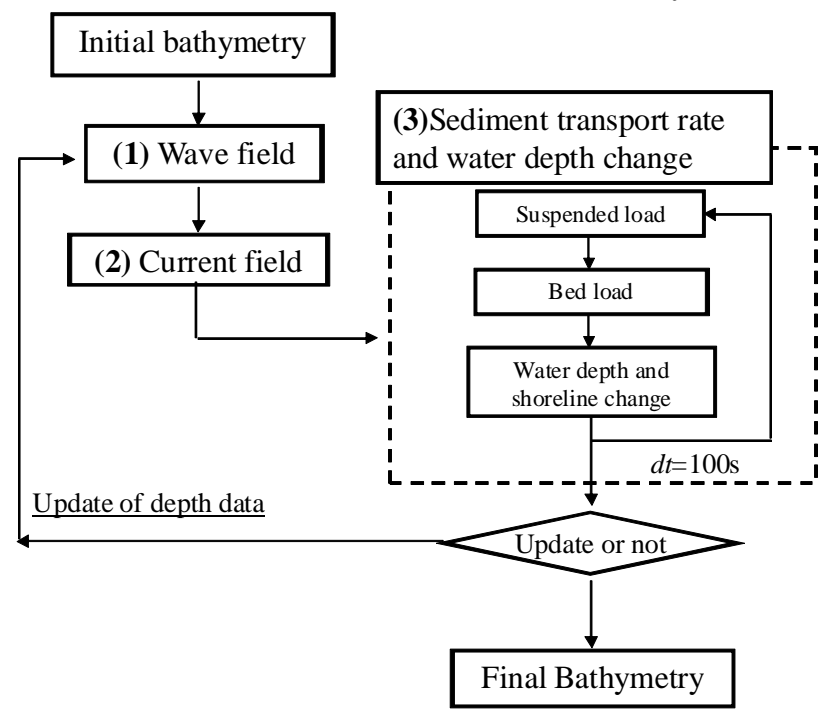

Figure 1. Comptaional flow of the presented three-dimensional morphodynamic model.

\section{Sediment Transport Rate and Water Depth Change}

The total sediment transport rate is defined as the sum of bed load and suspended load. The water depth and shoreline changes were computed by the continuity equation, as follows: 


$$
\frac{\partial h}{\partial t}=\frac{Q_{s}}{1-\lambda}+\frac{1}{1-\lambda}\left\{\frac{\partial}{\partial x}\left(q_{b x}+\varepsilon_{s}\left|q_{b x}\right| \frac{\partial h}{\partial x}\right)+\frac{\partial}{\partial y}\left(q_{b y}+\varepsilon_{s}\left|q_{b y}\right| \frac{\partial h}{\partial y}\right)\right\}
$$

where $h$ is the water depth. $q_{b x}$ and $q_{b y}$ are the bed loads, which are estimated based on Watanabe et al. (1986). $\varepsilon_{s}$ is the dimensionless coefficient. $Q_{s}$ is the difference between the upward sediment flux $F_{z}$ and the downward flux $w_{f} c$, as given by

$$
\begin{gathered}
Q_{s}=F_{z}-w_{f} c \\
F_{z}=(1-\gamma) c_{0} \alpha w_{f}\left(\frac{u_{*}}{w_{f}}-1\right) \quad\left(\begin{array}{l}
u_{*} \geq w_{f}: \gamma=0 \\
u_{*} \leq w_{f}: \gamma=1
\end{array}\right.
\end{gathered}
$$

where $\alpha(0 \leq \alpha \leq 1.0)$ is the dimensionless coefficient. $c_{0}$ is the concentration at reference point, $c_{0}=0.347 N_{c}^{1.77}$.

$$
N_{c}=\frac{0.688 \hat{u}_{w}^{2}}{1.13(s-1) g w_{f} T}
$$

$\hat{u}_{w}$ is the maximum orbital velocity at bottom. $S$ is the specific gravity of sand. $T$ is the wave period. The concentration of suspended sediment, $c$, is determined by solving the following depth-averaged advection diffusion equation, as given by

$$
\frac{\partial c}{\partial t}+\tilde{U} \frac{\partial c}{\partial x}+\tilde{V} \frac{\partial c}{\partial y}=\frac{\partial}{\partial x}\left(K_{x} \frac{\partial c}{\partial x}\right)+\frac{\partial}{\partial y}\left(K_{y} \frac{\partial c}{\partial y}\right)+\frac{Q_{s}}{\bar{\zeta}+h}
$$

where $K_{x}$ and $K_{y}$ are the diffusion coefficients, which are determined as a function of current velocity and water depth.

The bed load is based on Watanabe model(1986). The total bed loads are given by

$$
\overrightarrow{q_{b}}=\overrightarrow{q_{w}}+\overrightarrow{q_{c}}=\left\{\begin{array}{l}
q_{b x}=q_{w x}+q_{c x} \\
q_{b y}=q_{w y}+q_{c y}
\end{array}\right\}
$$

$\overrightarrow{q_{w}}$ is due to the wave orbital velocities at the bottom. $\overrightarrow{q_{c}}$ is due to the steady current velocity. These are estimated by

$$
\begin{aligned}
& \left.\overrightarrow{q_{w}}=A_{w}\left(u_{*}^{2}-u_{*_{c}}{ }^{2}\right) \overrightarrow{\hat{u}_{w}} / g\right) \\
& \left.\overrightarrow{q_{c}}=A_{c}\left(u_{*}^{2}-u_{*}^{2}{ }^{2}\right) \vec{U} / g\right)
\end{aligned}
$$

where $A_{w}$ and $A_{c}$ are the dimensionless coefficients. $u_{*}$ is the friction velocity. $u_{*}$ is the critical friction velocity. $\vec{U}$ is the steady current vector. In case the Q-3D mode is used, the bed load due to the nearshore current velocities at the sea bottom is determined. The coefficients $A_{w}$ and $A_{c}$ are given by a function of the median diameter $d_{50}$ (Shimizu et al, 1996) as

$$
\left.\begin{array}{c}
B_{w}=C_{w}\left(\sqrt{d_{50}} / w_{f}\right)^{3} \\
A_{w} / B_{w}=w_{f} \sqrt{0.5 f_{c w}} /\left\{(1-\lambda) s \sqrt{s g d_{50}}\right) \\
A_{c}=\beta A_{w}
\end{array}\right\}
$$

where $C_{w}$ is the dimensionless coefficient. $w_{f}$ is the fall velocity of sand. $f_{c w}$ is the sea-bottom friction factor. $\lambda$ is the porosity of the bed. $s$ is the specific gravity in the water.

The suspended load is determined by flux model, which is based on the two-dimensional advection diffusion equation, proposed by Sawaragi et al. (1986). In this model, the sediment transport rate due to the alongshore steady current in the run-up region is taken into account in order to predict the shoreline change.

\section{Injection Procedure of Nourished Sand}

The injection and movement of sand nourished at the eroded beach or offshore area are computed using the flux model as mentioned above. The injection of the nourished sand is expressed by water depth change due to the downward sediment flux. The injection process is computed using Eq.(8). In 
practice, as the amount of the injected sand is a bulk value, therefore, the injected bulk amount has to be converted to the value of concentration. Relationships between the concentration and bulk value are found by the trial and error computations.

\section{COMPUTED RESULTS AND DISCUSSIONS}

\section{Model Test}

Firstly, a model test of the morphodynamics between two large groins based on the field observation conducted by Uda et al. (2008) was carried out. The computational domain was set to an area of $1000 \mathrm{~m}$ in the cross-shore direction and $2000 \mathrm{~m}$ in the alongshore direction. An idealized bathymetry was used in this model test, as shown in Fig.2. A time series of input wave with two stormy conditions was set as shown in Fig. 3, based on the field data. The waves were set to oblique direction of 20degrees. Under the stormy wave conditions of (II) and (III), the Q-3D model was used to consider the effect of undertow velocity. The bathymetric change after 120 days was computed. Until the final bathymetry was obtained, the bathymetry was updated every 2days, namely the computations of wave and nearshore current modules were done 60 times. The grid size $\Delta x$ and $\Delta y$ in the computations were set to $20 \mathrm{~m}$. The dimensionless coefficients $C_{w}$ and $\beta$ in Eq.(11) were 1.955 and 10 , by trial and error computations. The median diameter $d_{50}$ was $0.2 \mathrm{~mm}$.

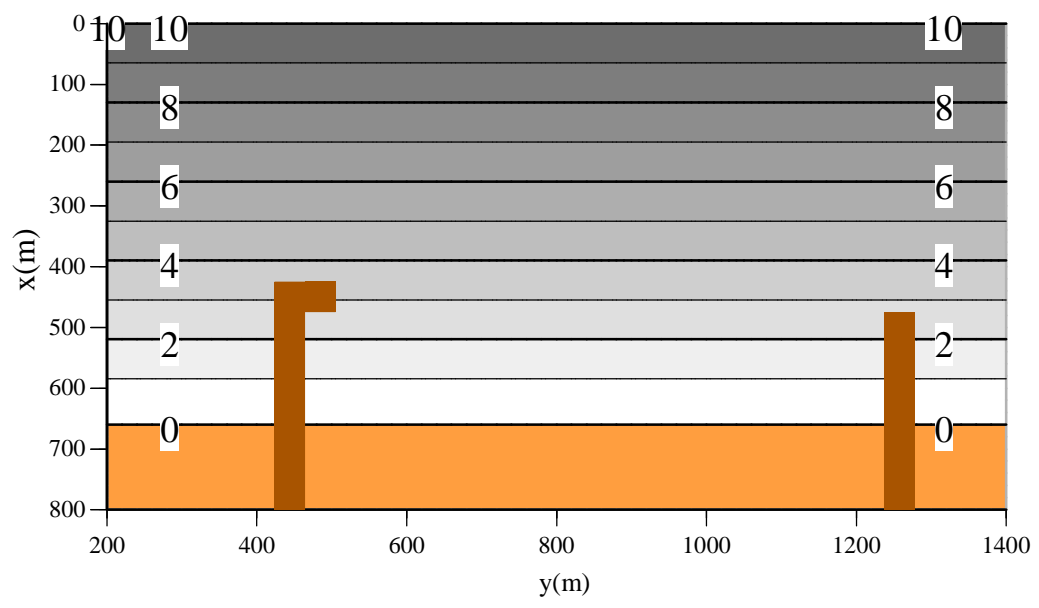

Figure 2. Initial bathymetry with two large groins.

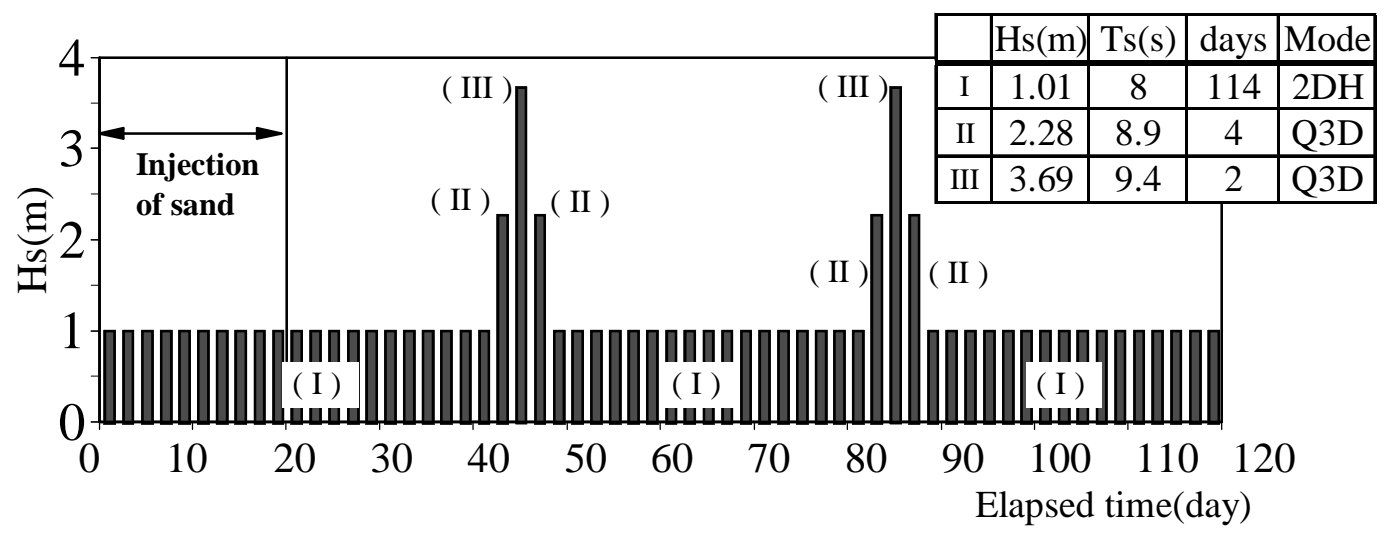

Figure 3. Input wave height time history with two stormy wave conditions.

Bathymetric change without offshore nourishment. A simulation for beach evolution between two groins without nourishment was carried out in order to confirm the performance of the presented model. Figs.4(a) and (b) show the computed significant wave height distribution and the depth-averaged 
nearshore current field for the initial bathymetry. It can be seen that alongshore current was computed between the groins. Figs.5(a) and (b) show the simulated bathymetries at 60 and 120 days after wave action. The presented model demonstrated that the shoreline around $y=600 \mathrm{~m}$ was gradually retreated and the other area in the downstream side was advanced, due to the alongshore sediment transport.

Bathymetric change with offshore nourishment. As shown in Fig.3, the sand material for nourishment was continuously injected, during 20days. The concentration of injected sand was set to $C=0.0001 \mathrm{in}$ an area of $10,000 \mathrm{~m}^{2}$. The total volume for 20days is corresponding to approximately $20,000 \mathrm{~m}^{3}$. Figs.6(a), (b), (c) and (d) show the computed bathymetries after nourishment around the water depth of $6 \mathrm{~m}$. Figs.7(a) and (b) show the cross-shore profile changes. From these figures, it was confirmed that sand hill was formed due to the injection of sand, and then the sand hill was diffused in the alongshore direction and moved to shoreward after the completion of the sand injection. The computed bathymetric change was qualitatively agreed with the field observation conducted by Uda et al. (2008).

Fig. 8 shows the comparison of shoreline changes after 120 days with and without the nourishment. In the computed bathymetry without nourishment, the shoreline was remarkably retreated in the up-side of the alongshore sediment transport, on the other hand, the shoreline in the down-side was advanced. In the computed result with nourishment, it was clear that shoreline retreat with nourishment was less than without nourishment. It was confirmed that although the nourishment at $6 \mathrm{~m}$ was not directly contribute the shoreline advance, the sand hill formed by the nourishment contributed the coastal stability, from the comparison of nearshore current patterns between computed result with and without nourishment as shown in Fig.9.

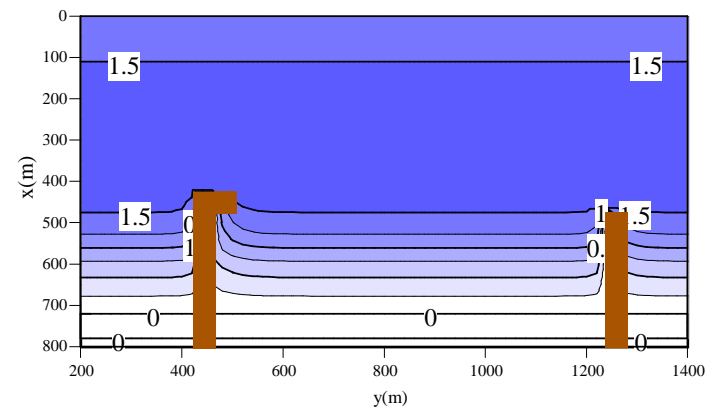

(a) Significant wave height distribution

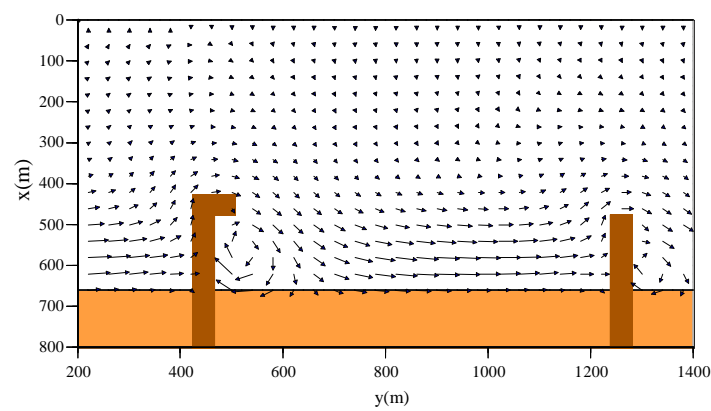

(b) Depth-averaged nearshore current field

Figure 4. Computed significant wave height distribution and the depth-averaged current field for the initial bathymetry $(\mathrm{Hs}=1.5 \mathrm{~m}, \mathrm{~T}=7.0 \mathrm{~s})$.

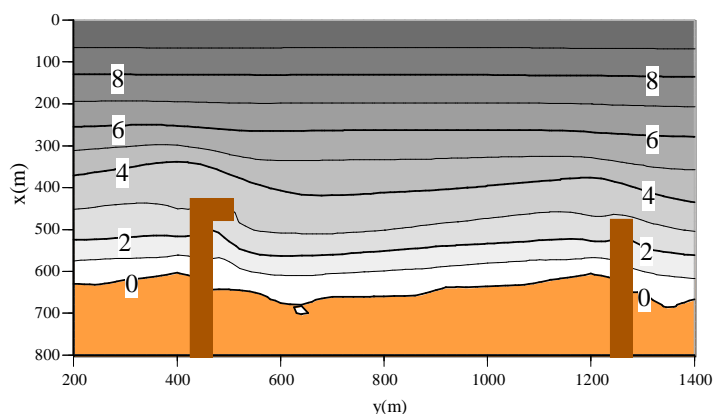

(a) 60days later

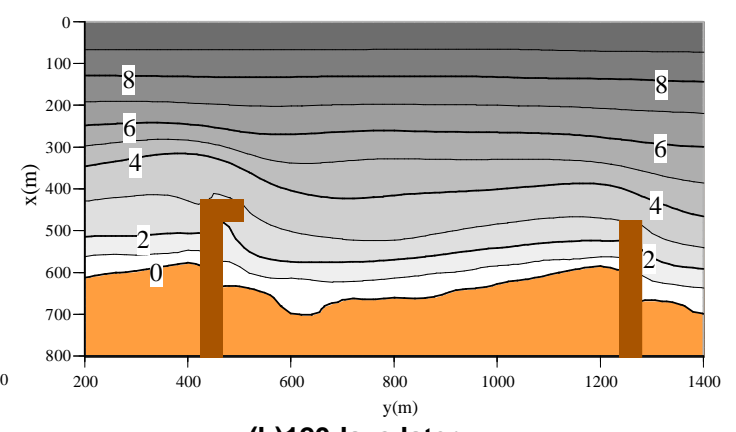

(b)120days later

Figure 5. Bathymetries after 60 and 120 days without offshore nourishment. 

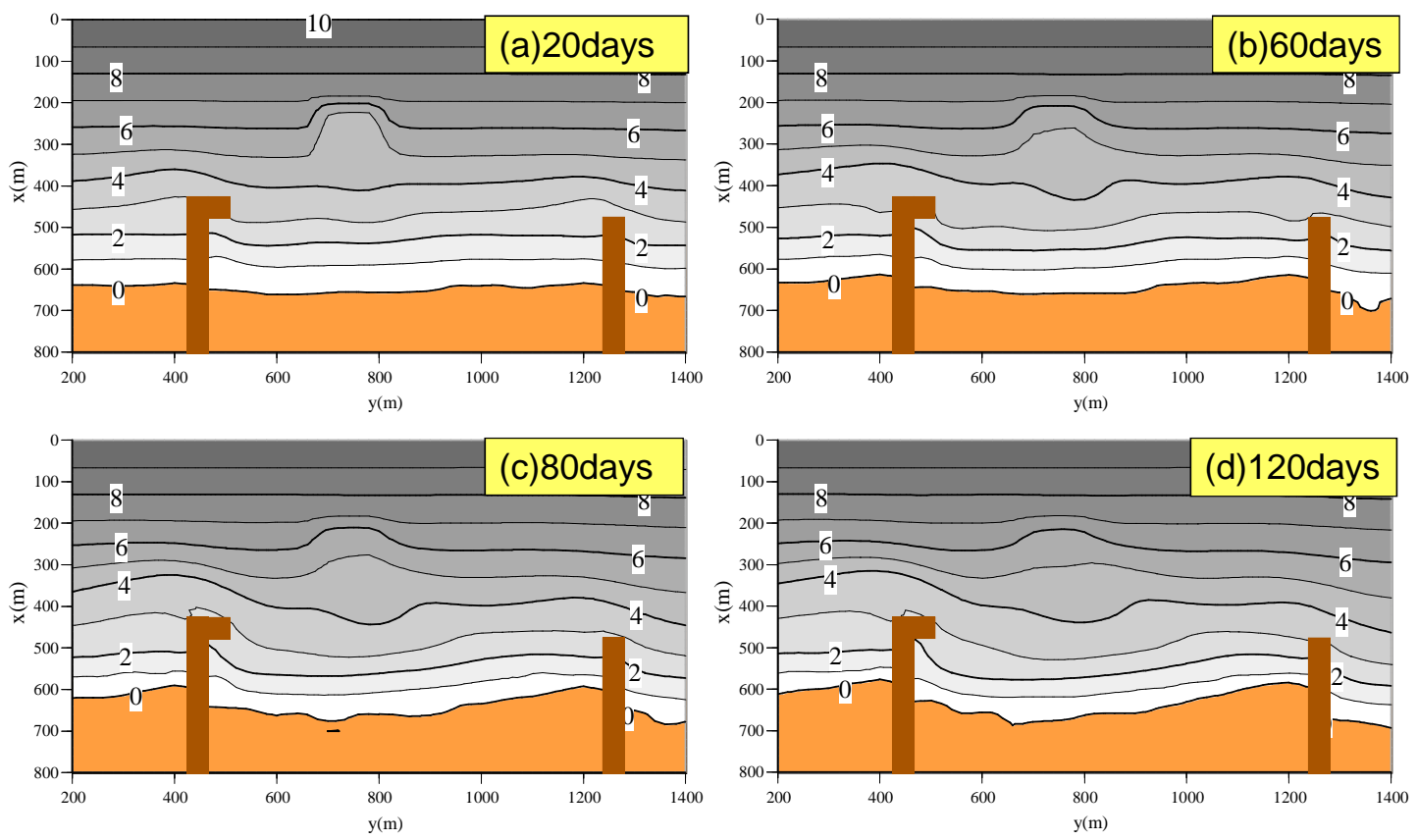

Figure 6. Computed bathymetries after 20, 60, 80 and 120 days with offshore nourishment.

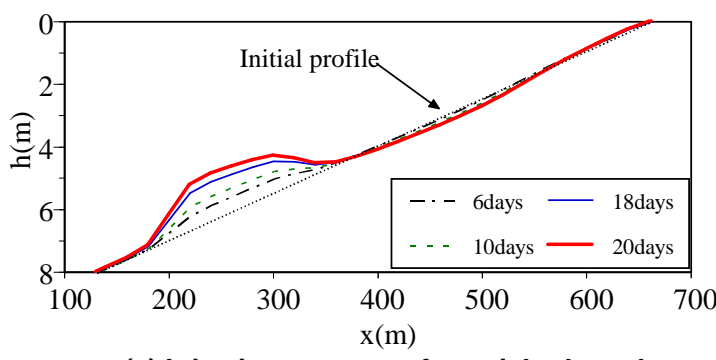

(a) Injection process of nourished sand

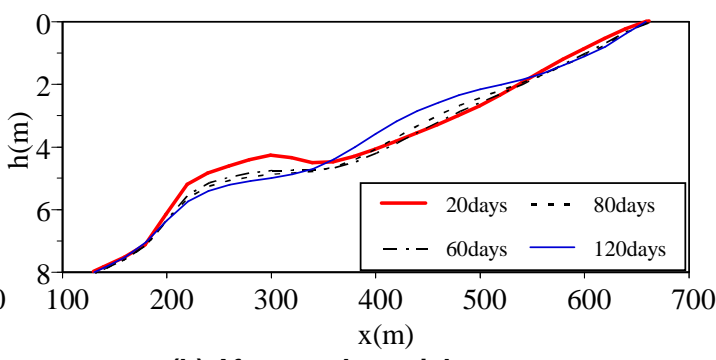

(b) After sand nourishment

Figure 7. Cross-shore profile changes due to offshore nourishment.

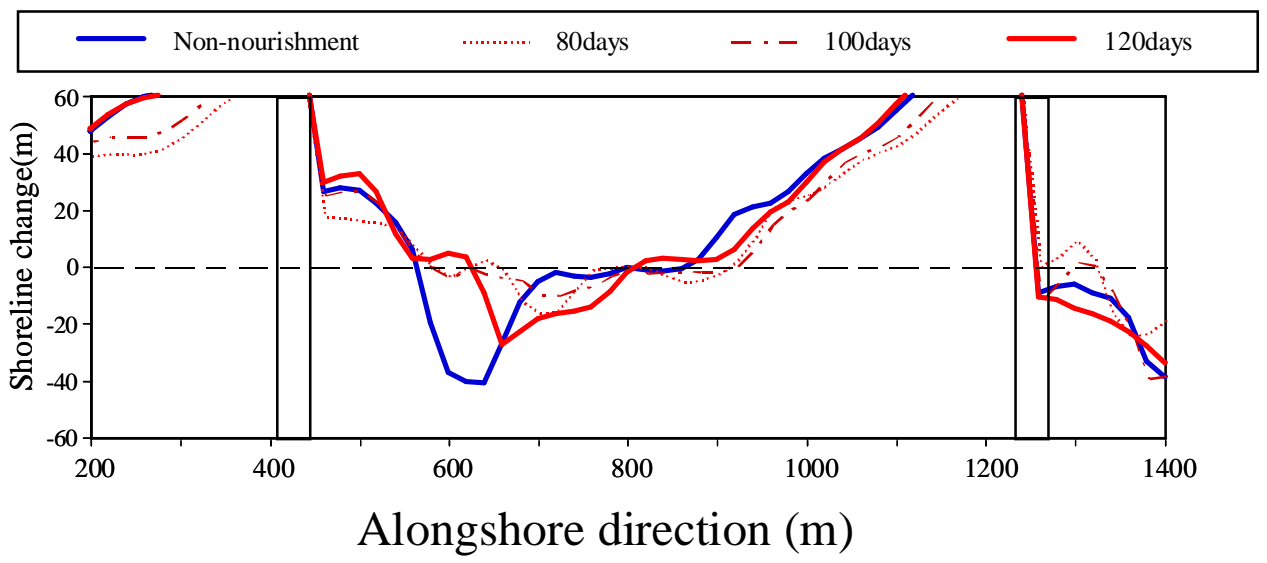

Figure 8. Comparison of shoreline change between nourishment and non-nourishment. 

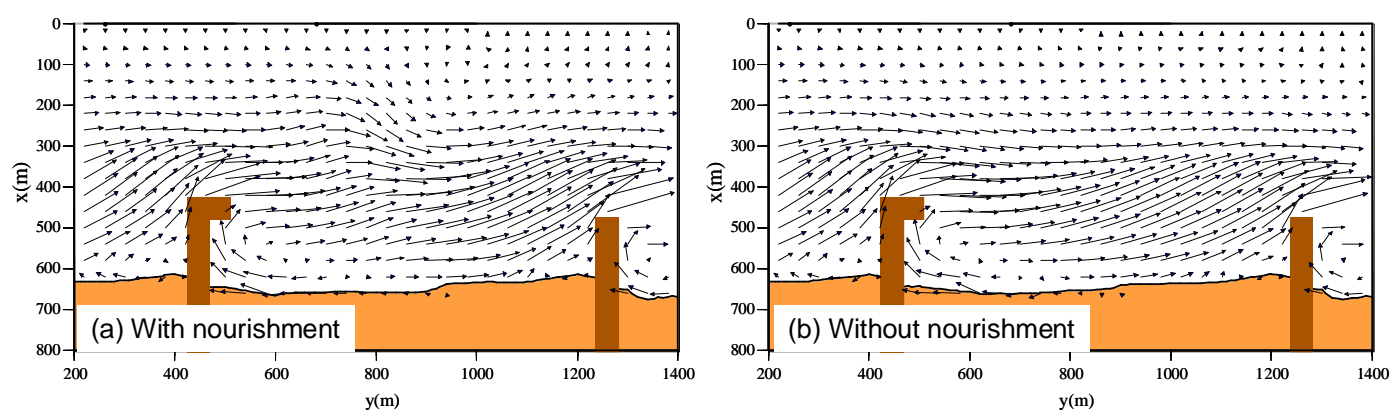

Figure 9. Comparison of nearshore current field between nourishment and non-nourishment.

\section{Model Verification to Field Observation}

Field observation site and results. The presented model was applied to a field observation associated with the shoreface nourishment conducted in the Egmond aan Zee Coast in the Netherlands (van Duin and Wiersma, 2002; van Duin, 2002; van Duin et al., 2004). The Egmond coast has three bar system, which consists of outer bar, inner bar and swash bar. The field observation was carried out in June 1999 to April 2002. From June to September 1999, the shoreface nourishment, which is the nourishment in front of the original outer bar, was carried out. The total sand volume of approximately $900,000 \mathrm{~m}^{3}$ was injected during the period.

Figs.10, 11 and 12 show measured bathymetries in June, September 1999 and May 2000, respectively. In Figs.11 and 12, red color and blue color represent deposition and erosion areas, respectively. Fig. 13 shows the comparison of cross-shore profiles at the section of $y=0 \mathrm{~m}$. A sand bar due to the nourishment at offshore side of the outer bar was formed. In the winter period from September 1999 to May 2000, the original outer bar migrated shoreward and a trough was formed between 350 and $450 \mathrm{~m}$ cross-shore distance $(x)$, and then the inner bar was formed behind the trough. In this winter period, the water depth in the nourished area slightly changed and the nourished sand was remained. Therefore, it was found that the nourished sand hill was effective as a submerged breakwater.

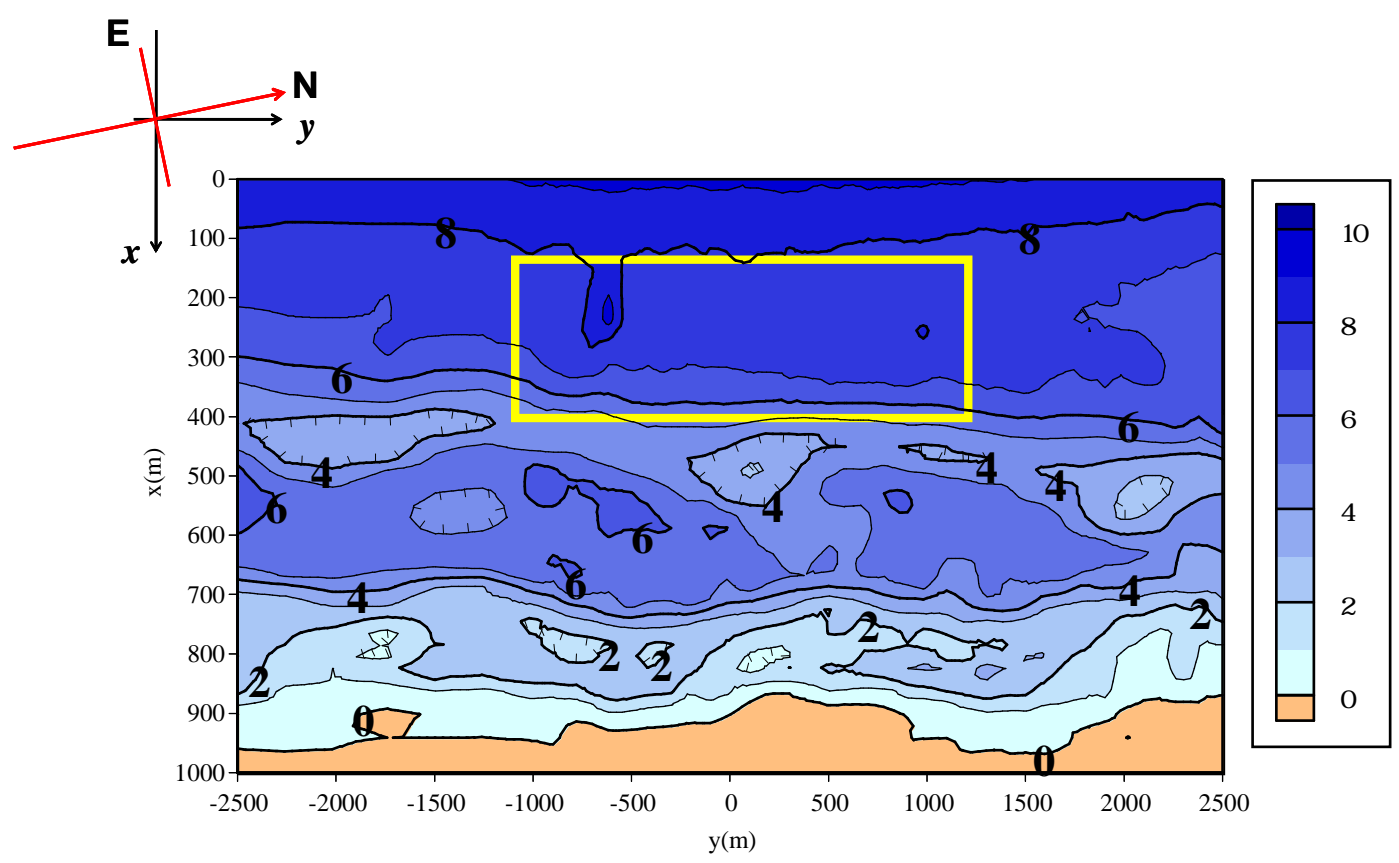

Figure 10. Measured bathymetry at Egmond aan Zee coast in June, 1999. (Before shoreface nourishment) 


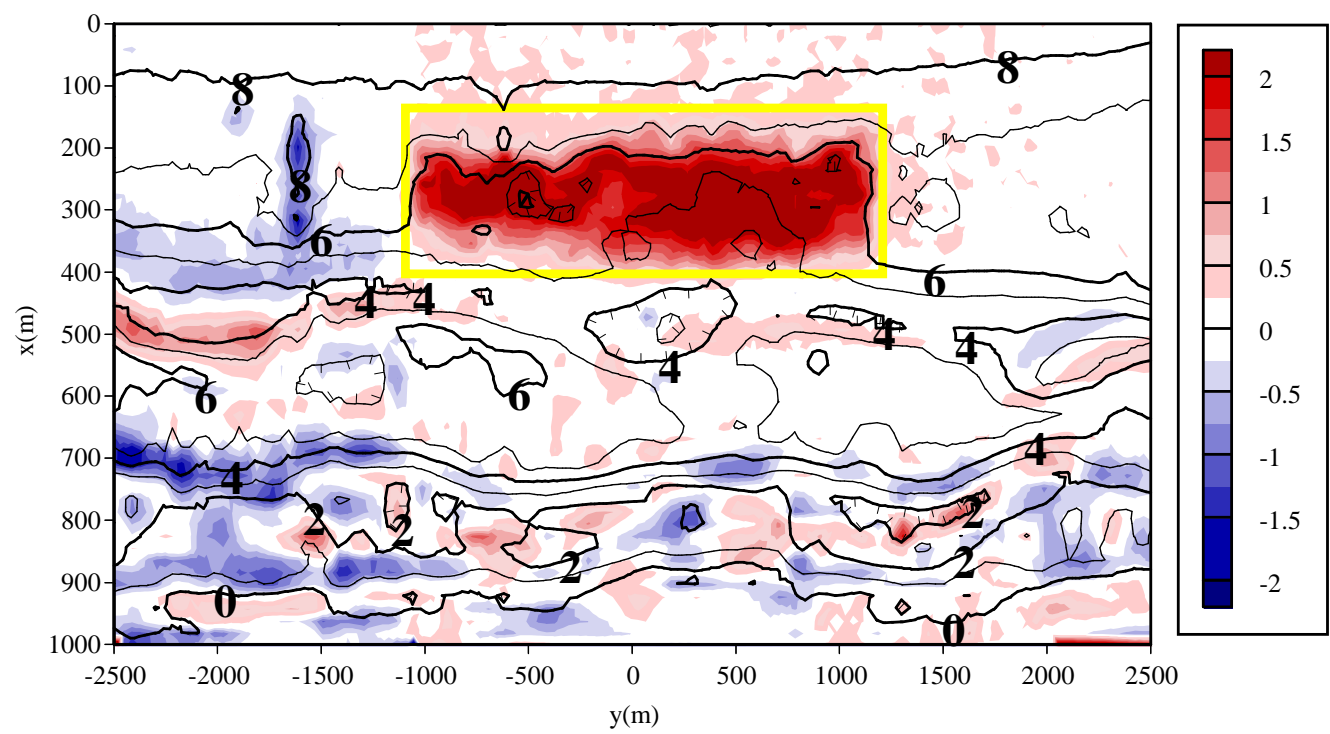

Figure 11. Measured bathymetry at Egmond aan Zee coast in June, 1999 (shoreface nourishment).

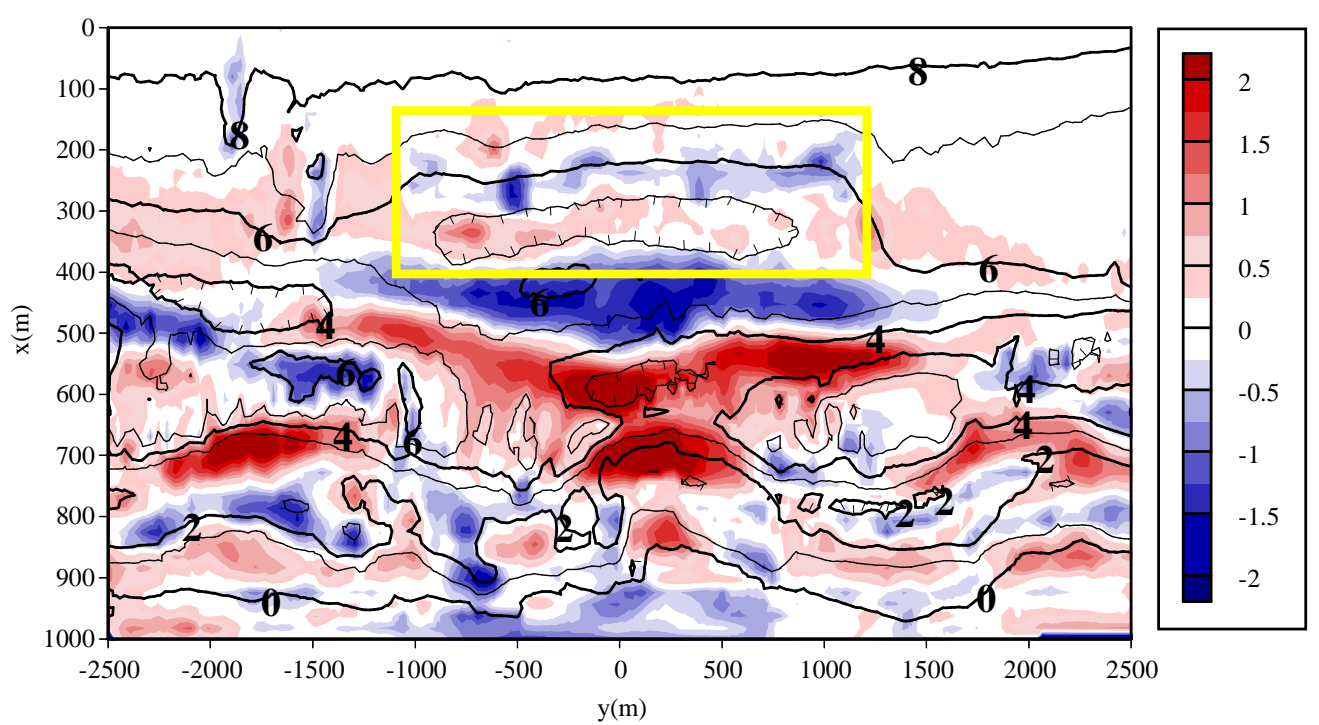

Figure 12. Measured bathymetry at Egmond aan Zee coast in May 2000 (Aftere shoreface nourishment).

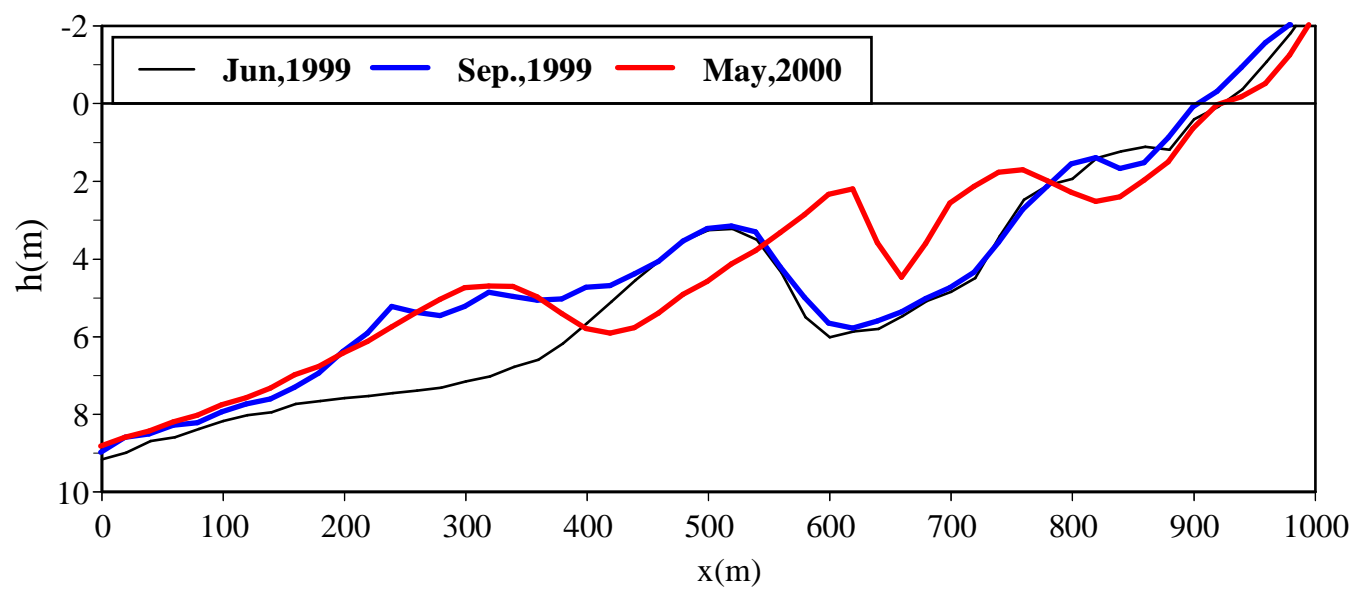

Figure 13. Comparison of cross-shore profiles at Egmond aan Zee coast in June and Septermber,1999 and May, 2000. 
Computational set-up. In this model verification, the process of injection from June to September in 1999 and the topographical change in the winter season from September 1999 to May 2000 after the injection were simulated. The computational domain and the initial bathymetry were set to an area as shown in Fig.10. The order of wave conditions was made as represented in Fig.14 and Table 1. The wave conditions are based on the wave data made by van Duin (2002), but the wave height less than $1 \mathrm{~m}$ was neglected. The reason is that because the wave actions less than $1 \mathrm{~m}$ in the presented model did not contribute to the topographical changes. The influence of tidal flow was not taken into account, although the Egmond coast has the tidal range of approximately $2 \mathrm{~m}$. Sand injection by step 10 was carried out under wave conditions less than the wave height of $1 \mathrm{~m}$, after that beach evolution was computed. The wave direction was set to the averaged-value of the data from van Duin (2002). In a rectangular area in Fig.10, the concentration of $C=0.00005$ was set by 10 steps. The total volume is approximately corresponding to $900,0000 \mathrm{~m}^{3}$. The grid $\Delta x$ and $\Delta y$ in the computations were set to $20 \mathrm{~m}$ and 40m, respectively. The dimensionless coefficients $C_{w}$ and $\beta$ in Eq.(11) were 9.775 and 5.0, by trial and error computations. The median diameter $d_{50}$ was $0.2 \mathrm{~mm}$.

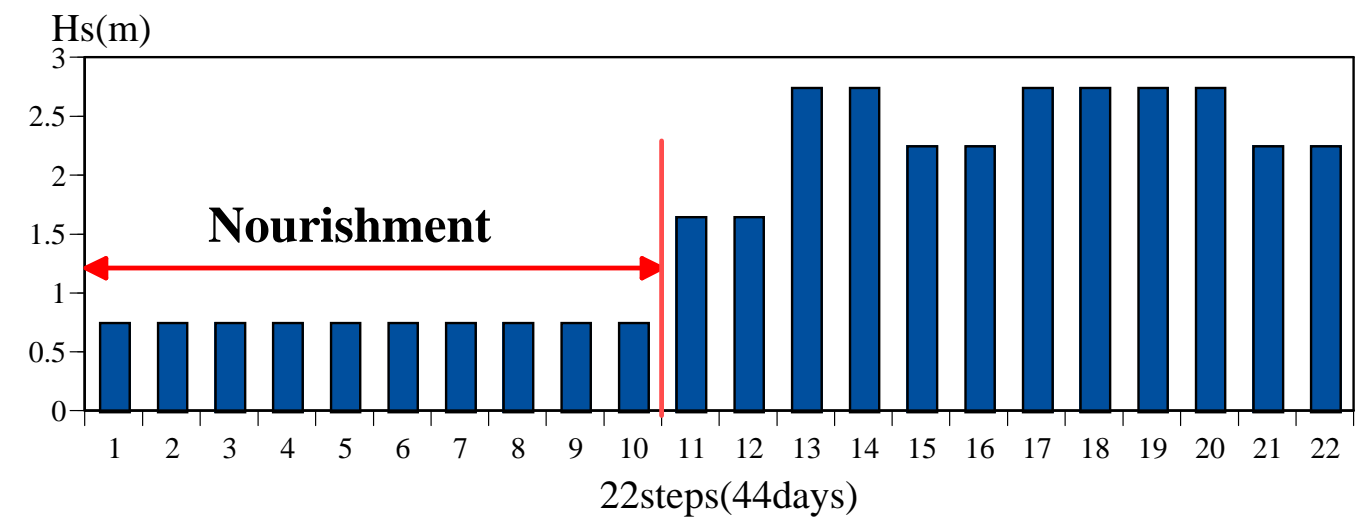

Figure 14. Comparison of cross-shore profiles at Egmond aan Zee coast in June and Septermber,1999 and May, 2000.

\begin{tabular}{|c|c|c|c|c|}
\hline Step & $H s(\mathrm{~m})$ & $T s(s)$ & Mode & Wave direction \\
\hline $1-10$ & 0.76 & 7.0 & $2 \mathrm{DH}$ & \multirow{7}{*}{$-11\left(281^{*}\right)$} \\
\hline 11,12 & 1.65 & 7.0 & $2 \mathrm{DH}$ & \\
\hline 13,14 & 2.75 & 8.3 & Q3D & \\
\hline 15,16 & 2.25 & 7.8 & Q3D & \\
\hline 17,18 & 2.75 & 8.5 & Q3D & \\
\hline 19,20 & 2.75 & 9.5 & Q3D & \\
\hline 21,22 & 2.25 & 8.7 & Q3D & \\
\hline
\end{tabular}

Computed results and discussions. The computed bathymetry with erosion/sedimentation plot and cross-shore profile changes at $y=0 \mathrm{~m}$ during the injection process from June to September 1999 are demonstrated in Figs.15 and 16. During the injection process in Figs.15 and 16, the sand hill was formed by step 10 in front of the original outer bar. Comparing with the measured data in Fig.11, the computed result may be acceptable and qualitatively agree with the measured data. However, the shape of the computed sand hill is a little different. Therefore, the computational method of the injection process has to be reinvestigated.

Fig.17 shows the computed bathymetry at 8 months later after nourishment, corresponding to the measured bathymetry in Fig.12. Comparing with the measured result, the erosion and deposition in front of the nourished area were qualitatively reproduced. Fig. 18 shows the computed cross-shore profile changes after the nourishment. From this figure, it was found that the presented model 
reproduced the shoreward migration of the nourished sand and the inner bar formation between $x=650$ and $750 \mathrm{~m}$.

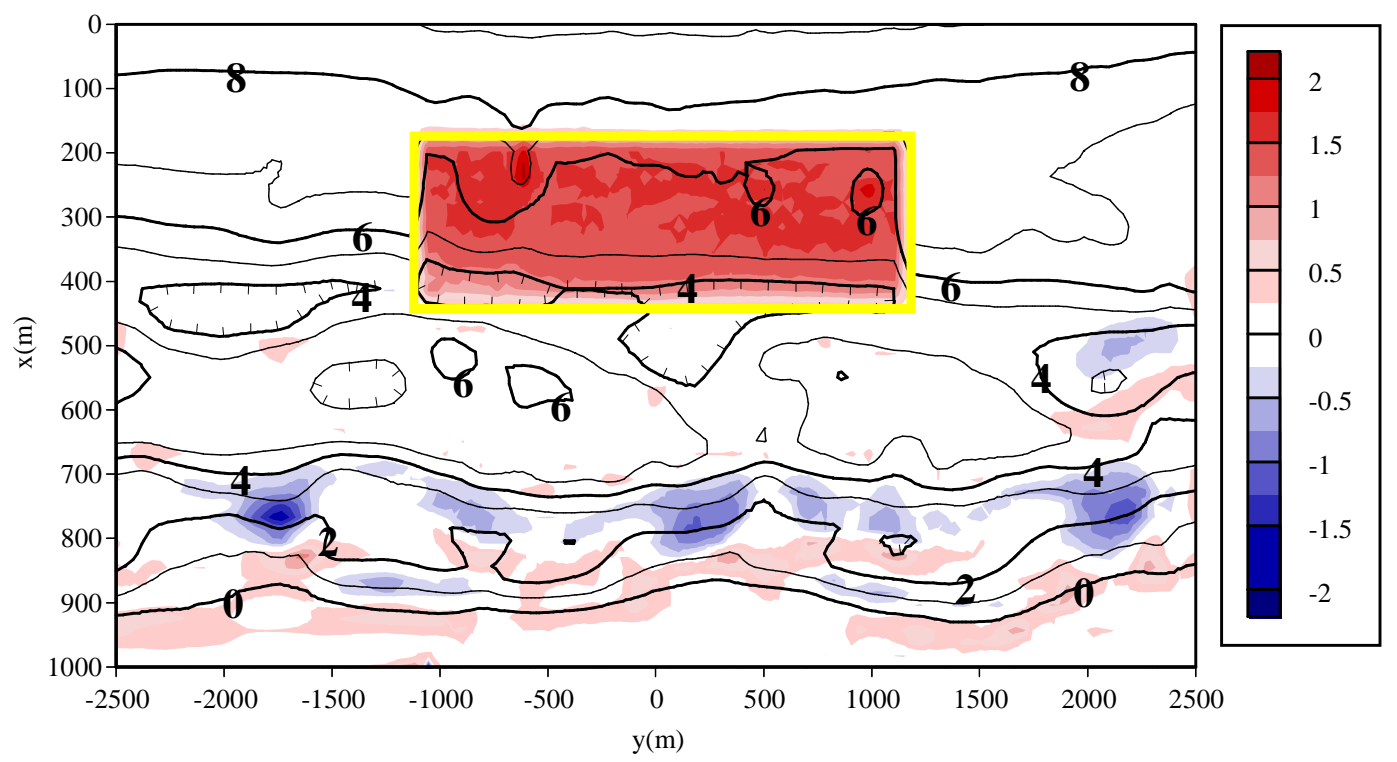

Figure 15. Comparison of cross-shore profiles at Egmond aan Zee coast in June and Septermber,1999 and May, 2000.

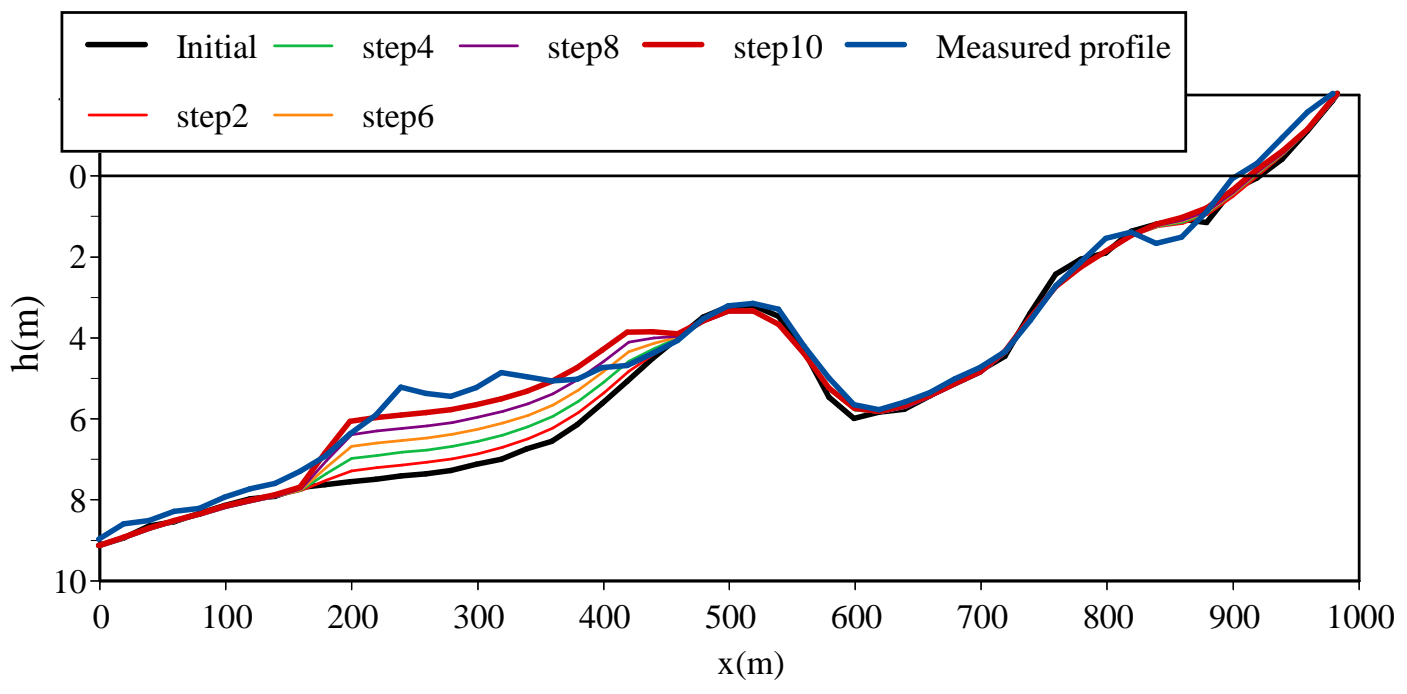

Figure 16. Computed cross-shore profile change at $y=0 \mathrm{~m}$ during the sand injection (from June to September, 1999). 


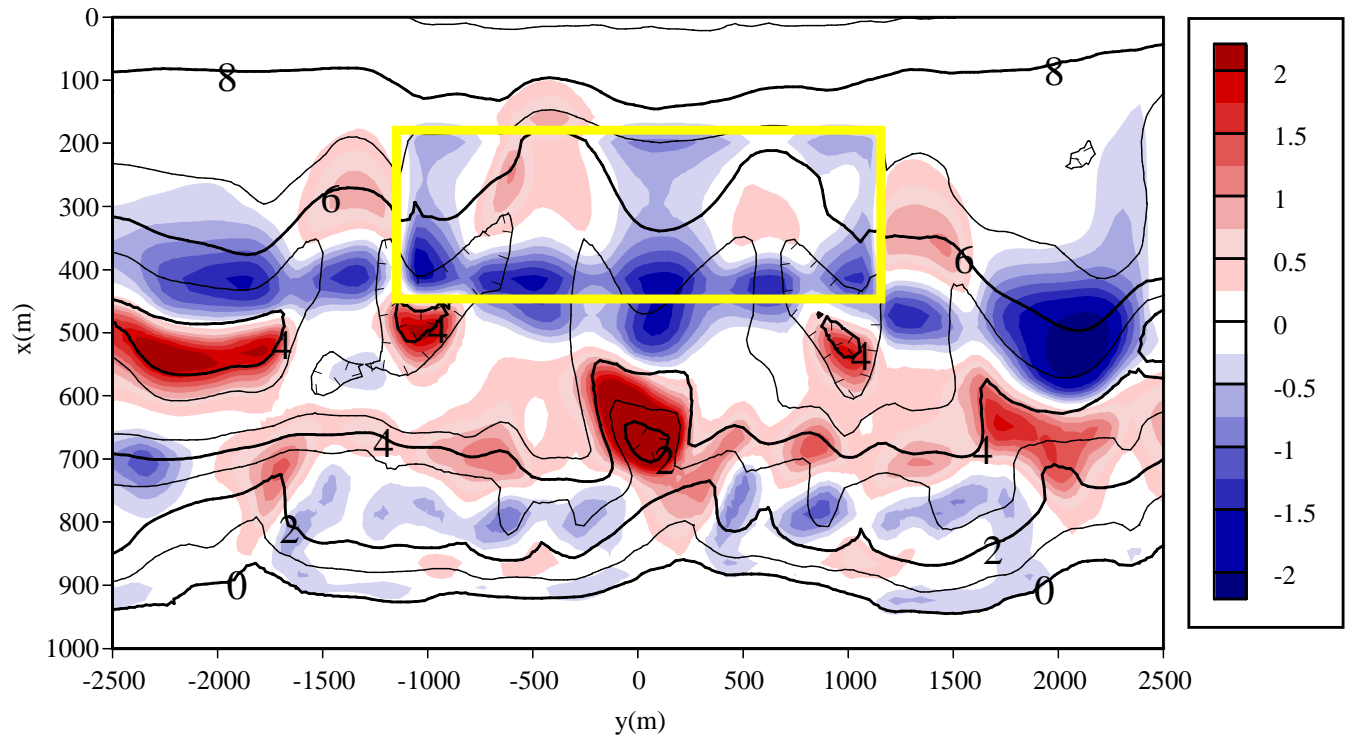

Figure 17. Comparison of cross-shore profiles at Egmond aan Zee coast in June and Septermber,1999 and May, 2000.

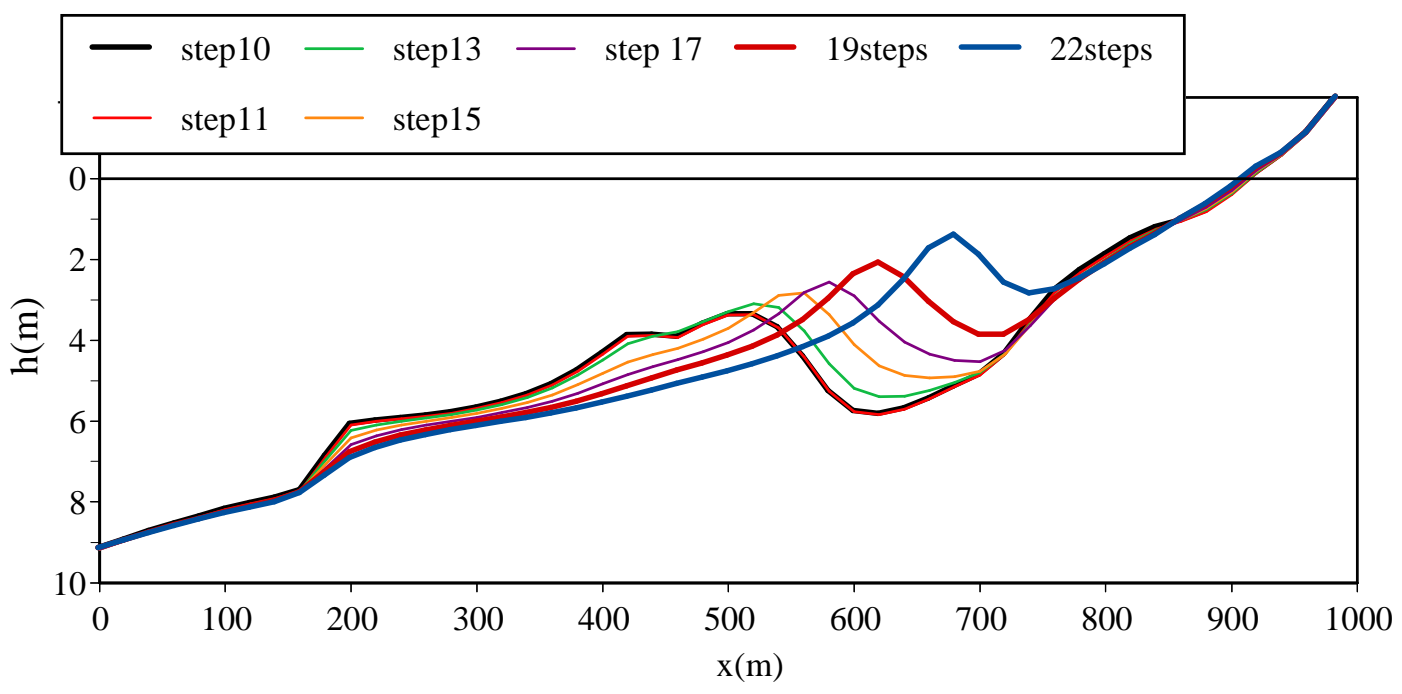

Figure 18. Computed cross-shore profile change from step10 to 22 (after completing the injection from June to September, 1999).

Figs.19(a),(b) and (c) show comparisons of cross-shore profiles at $y=0 \mathrm{~m},-1750 \mathrm{~m}$ and $+1750 \mathrm{~m}$ between the computed and measured results. From these comparisons, some aspects are derived as follows:

- From the computed results in Figs. 18 and 19(a), the nourished sand was gradually migrated shoreward. Although the tendency of the migration of the nourished sand was similar to the measured result, a remarkable trough as shown in the field measurement was not reproduced.

- From the measured profiles in Figs.19(b), the inner bar was formed around $x=700 \mathrm{~m}$, but the outer bar was not migrated. From the computed results, the computed out bar slightly moved shoreward and also the inner bar was formed around $x=750 \mathrm{~m}$. In this section, it was confirmed that the computed results qualitatively agreed with the measured results.

- From Figs.19(c), the outer bar at $x=500$ in the field measurement was not moved, on the other hand in the prediction the outer bar was remarkably moved shoreward.

From the computed results mentioned above, although the computed bathymetrical change showed more complex pattern than the measured results, it was confirmed that the presented model could qualitatively reproduce the topographical change after shoreface nourishment. 


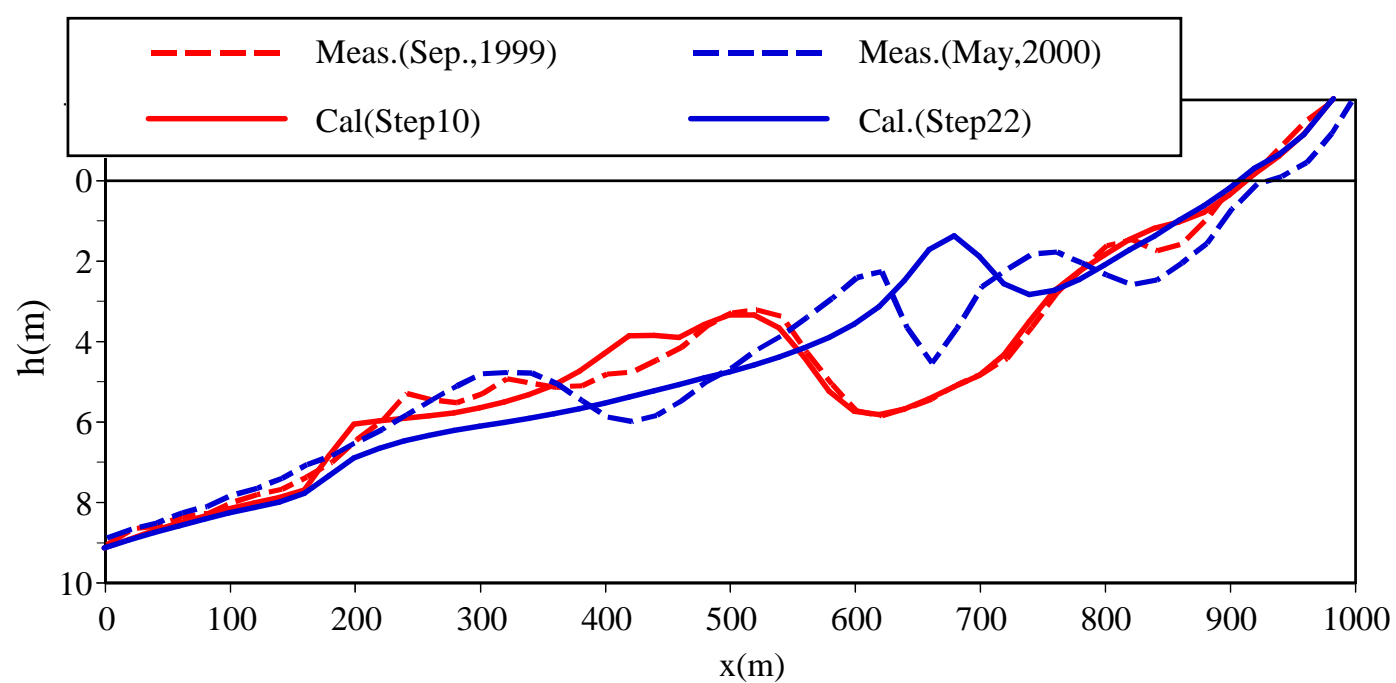

(a) Cross-shore profiles at $y=0 \mathrm{~m}$

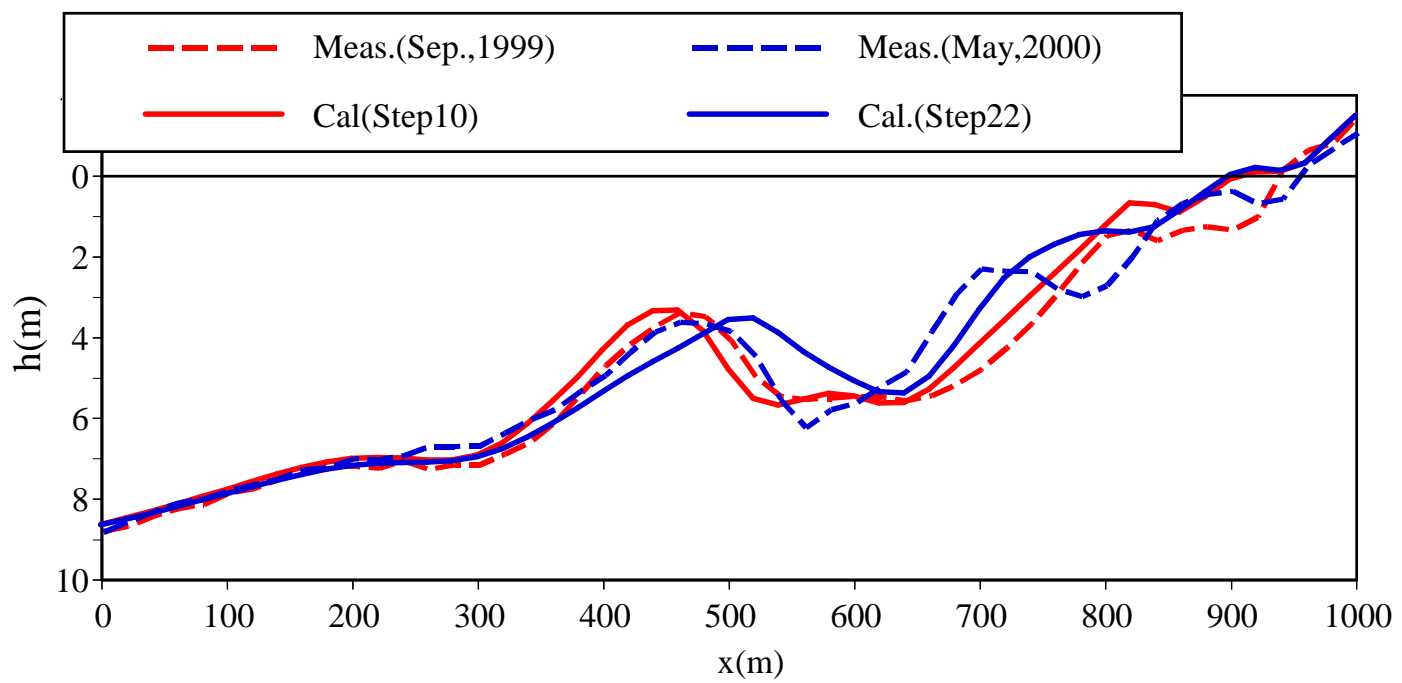

(b)Cross-shore profiles at $y=-1750 m$

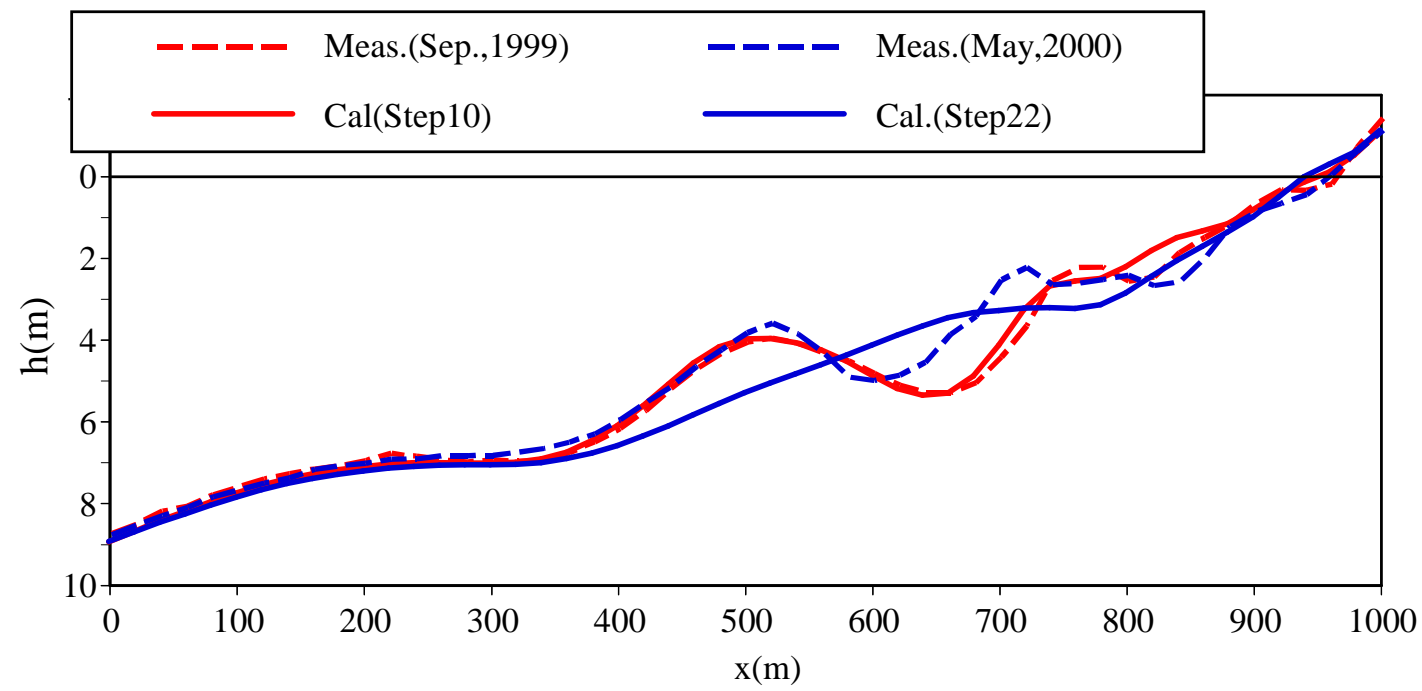

(c) Cross-shore profiles at $y=+1750 \mathrm{~m}$

Figure 19. Comparison of computed cross-shore profiles with the measured results (from September, 1999 to May, 2000). 


\section{CONCLUSIONS}

In this study, a simple 3D model for predicting the beach evolution after sand nourishment was developed. Firstly, a model test with two large groins was carried out in order to investigate the performance of the model. Secondly, model verification against the field observation regarding to shoreface nourishment conducted at the Egmond aan Zee in the Netherlands. From the computed results, some conclusions are derived as follows:

\section{Model test}

- From the results of the offshore nourishment, it was confirmed that the presented model can simulate the sand hill formation due to nourishment and the behavior such as the diffusion of nourished sand.

- Comparing with the computed result without nourishment, it was confirmed that the offshore nourishment is an effective technique to preserve the shoreline.

- The computed result was in qualitatively agreement with the field measurement conducted by Uda et al. (2008)

\section{Field verification}

- After the shoreface nourishment, the nourished sand in the computation was gradually migrated shoreward and the inner bar was formed between $x=650$ and $750 \mathrm{~m}$. Although the tendency was similar to the measured result, a remarkable trough as shown in the field measurement was not reproduced.

- Although some discrepancies between the field measurements and the computations were found, the erosion and deposition in front of the nourished area were qualitatively reproduced.

- It was confirmed that the presented model can simulate the sand hill formation due to nourishment and the computed nourishment process shows reasonable result.

\section{Problems of the Present Model and Future Works}

In this model, the injection process of nourished sand was computed by downward flux for the concentration of suspended sediment. The advection diffusion equation was simultaneously calculated. The total volume of injected sand was influenced by some parameters such as diffusion coefficients, pick-up function in Eq.(5) and (6) and so on. To convert from the concentration to the sand volume, some trial and error computation was required. The injection process will be reinvestigated.

In the model verification using field data for the Egmond shoreface nourishment, the Egmond has tidal rang over $2 \mathrm{~m}$. However, the presented model could not consider the sea level change due to the tidal prism and the tidal currents. To get more good accuracy of the prediction, the model should be modified so as to take account the tidal current.

\section{ACKNOWLEDGMENTS}

We would like to thank Dr. D.J. Walstra of Delft Hydrourics in the Netherlands for providing us with the bathymetry data set regarding with shoreface nourishment at Egmond aan Zee in the Netherlands.

\section{REFERENCES}

De Vriend, H.J., J. Zyserman, J. Nicholson, J.A. Roelvink, P. Pechon, and H.N. Southgate. 1993. Medium-term 2DH coastal area modeling, Coastal Engineering, 21, 193-224.

Grunnet, N.M. and B.G. Ruessink. 2005. Morphodynamic response of nearshore bars to a shoreface nourishment, Coastal Engineering, 52, 119-137.

Hanson, H. and M. Larson. 2000. Simulating coastal evolution using a new type of N-line model, Proceedings of $27^{\text {th }}$ International Conference on Coastal Engineering, ASCE, 2808-2821.

Kuchiishi, T. K. Kato, M. Kuroiwa, Y. Matsubara and H. Noda. 2004. Field verification of a numerical Q-3D nearshore current model, Proceedings of $29^{\text {th }}$ International Conference on Coastal Engineering, ASCE, 1367-1379. 
Kuroiwa, M., H. Noda and Y. Matsubara. 1998. Applicability of a quasi-three dimensional numerical model to nearshore currents, Proceedings of $26^{\text {th }}$ International Conference on Coastal Engineering, ASCE, 815-828.

Kuroiwa, M., J.W. Kamphuis, T. Kuchiishi, Y. Matsubara and H. Noda. 2004. Medium-term Q-3D coastal area model with shoreline change around coastal structures, Proceedings of $29^{\text {th }}$ International Conference on Coastal Engineering, ASCE, 2194-2206.

Kuroiwa, M., T. Kuchiishi and Y. Matsubara. 2006. Prediction System of 3D Beach Evolution with 2DH and Q3D Hydrodynamic Modes, Proceedings of $16^{\text {th }}$ International Offshore and Polar Engineering Conference, 751-757.

Kuroiwa, M., T. Kuchiishi, K. Kato, S. Sunagawa and Y. Matsubara. 2008. Applicability of coastal area model to morphodynamic around river mouth, Proceedings of $31^{\text {st }}$ International Conference on Coastal Engineering, ASCE, 2218-2230.

Lesser, G.R., J.A. Roelvinka, J.A.T.M. van Kestera and G.S. Stelling. 2004. Development and varidation of three-dimensional morphological model, Coastal Engineering, 51, 881-915.

Mase, H. 2001. Multi-directional random wave transformation model based on energy balance equation, Coastal Engineering Journal, 43, No.4, 317-337.

Nishimura,H. 1988. Computation of nearshore current. In: Horikawa, K. (Ed.), Nearshore Dynamices and Coastal Process. In University of Tokyo Press, Japan, 271-291

Ojeda, E., B.G. Ruessink and J. Guillen. 2008. Morphodynamic response of a two-barred beach to a shoreface nourishment, Coastal Engineering, 55, 1185-1196.

Sawaragi, T., Lee, J.S. and I. Deguchi. 1986. A new model for prediction of beach deformation around river mouth, Proceedings of International Symposium on Ocean Space Utilization, 85, 229-236.

Shibutani, Y., M. Kuroiwa and Y. Matsubara. 2008. N-line beach evolution model considering advection and diffusion effects of nourished sand, Proceedings of $18^{\text {th }}$ International Offshore and Polar Engineering Conference, 713-720.

Shimizu, T., A. Yamada and A. Watanabe. 1996. Coefficient and cross-shore distribution of alongshore sediment transport rate, Proceedings of Coastal Engineering, JSCE, Vo.43, 571-575. (in Japanese)

Uda, T., T. Kumada, and M. Serizawa. 2004. Predictive model of change in longitudinal profile in beach nourishment using sand of mixed grain size, Proceedings of $29^{\text {th }}$ International Conference on Coastal Engineering, ASCE, 3378-3390.

Uda, T., Y. Tashiro and H. Nagayama. 2008. Observation of sand movement after offshore nourishment by sea bottom survey using narrow-multi-beam measurement, Annual Journal of Coastal Engineering,Vol.55, JSCE, 776-780. (in Japanese)

van Duin, M.J.P. 2002. Evaluation of the Egmond shoreface nourishment, Part III: Validation of morphological modeling Delft3D-MOR, WL|Delft Hydraulics report, Z3054/Z3148.

van Duin, M.J.P. and N.R. Wiersma. 2002. Evaluation of the Egmond shoreface nourishment, Part I: Dtata analysis, WL|Delft Hydraulics report, Z3054/Z3148.

van Duin, M.J.P., N.R. Wiersma, D.J.R. Walstra, L.C. van Rijn and M.J.F. Stive. 2004. Nourishing the shoreface: observation and hindcasting of the Egmond case, The Netherlands, Coastal Engineering, Vol.51, 813-837.

Watanabe, A., K. Maruyama, T. Shimizu and T. Sakakiyama, 1986. A numerical prediction model of three-dimensional beach deformation around a structure, Coastal Eng. in Japan, Vol.29, 179-194. 